\title{
Efecto de la aplicación de ácido láctico sobre Listeria monocytogenes en carne envasada al vacío en Uruguay
}

\section{Effect of lactic acid application on Listeria monocytogenes in vacuum packed meat in Uruguay}

Brugnini, Giannina (1); Acquistapace, María Jesús (1); Rodríguez, Soledad (1); Rufo, Caterina (1). (1) Área de Alimentos y Nutrición, Instituto Polo Tecnológico de Pando, Facultad de Química, Universidad de la República, Canelones, Uruguay.

Contacto: gbrugnini@fq.edu.uy

RECIBIDO: 22/3/2018 - APROBADO: 4/6/2018

\begin{abstract}
Resumen
En este trabajo se evaluó el efecto de la aplicación de ácido láctico en carne envasada al vacío sobre el crecimiento de Listeria monocytogenes, utilizando cepas aisladas de frigoríficos nacionales. Se aislaron e identificaron 35 cepas de Listeria: 29 L. innocua y 6 L. monocytogenes pertenecientes a más de un serotipo. Todos los aislamientos presentaron sensibilidad al ácido láctico in vitro. La concentración mínima inhibitoria en TSB-YE fue de 0,3\% y la concentración mínima bactericida, de $0,7 \%$.

En muestras de carne inoculadas con el aislado L100A1 tratadas con ácido láctico al 2,5\%, envasadas al vacío y conservadas a $4{ }^{\circ} \mathrm{C}$, se logró una reducción inicial de L100A1 de 1,1 log; al final de las ocho semanas la reducción había alcanzado $1,5 \mathrm{log}$, mostrando un efecto sinérgico entre el ácido láctico y el envasado al vacío. A concentraciones de ácido láctico de 5\% no se observó sinergia y la inhibición de 1,4log inicial se mantuvo constante en el tiempo. En suma, el uso de ácido láctico entre 2,5 y $5 \%$ en carne envasada al vacío reduce significativamente los recuentos de L. monocytogenes y puede utilizarse como estrategia adicional para su control en cortes cárnicos de alto valor. Palabras clave: Inocuidad, microorganismos patógenos, productos cárnicos.

Abstract

In this work, the effect of the application of lactic acid on Listeria monocytogenes growth was evaluated in vacuum packed meat using strains isolated from local slaughter houses. Thirty-five strains of Listeria were isolated and identified: 29 L. innocua and 6 L. monocytogenes belonging to more than one serotype. All the isolates showed sensitivity to lactic acid in vitro. The minimum inhibitory concentration in TSB-YE was $0,3 \%$ and the minimum bactericidal concentration was $0,7 \%$. The L100A 1 isolate was used in the meat study. In meat samples treated with $2,5 \%$ lactic acid, packed in vacuum and stored at $4{ }^{\circ} \mathrm{C}$, an initial reduction of L100A1 of $1,1 \log$ was achieved. By the end of eight weeks the reduction had reached 1,5 log showing a synergistic effect between lactic acid and vacuum packaging. When $5 \%$ lactic acid concentrations were used, no synergy was observed and the initial 1,4 log growth inhibition remained constant over time. In sum, the use of lactic acid at concentrations between 2,5 and $5 \%$ in vacuum packed meat significantly reduces $L$. monocytogenes counts and can be used as an additional hurdle in high value meat cuts. Keywords: Food Safety, pathogenic microorganisms, meat products.
\end{abstract}

\section{Introducción}

Listeria monocytogenes es una bacteria patógena causante de listeriosis, una enfermedad rara pero severa con una alta tasa de mortalidad (Buchanan, et al., 2017). Tanto en Estados Unidos como en la Unión Europea se evidenció una tendencia creciente en el número de brotes de listeriosis entre los años 2008 y 2015 (EFSA-ECDC, 2016; CDC, 2014). En Uruguay, en el año 2016 hubo un aumento de casos de listeriosis invasiva, y se reportaron 13 casos de los cuales cuatro fueron letales (MSP, 2017).

L. monocytogenes puede crecer en ausencia de oxígeno, en un amplio rango de $\mathrm{pH}$ (entre $4,4-9,4)$ y a temperatu- ras de refrigeración (Nychas, et al., 2008), y es uno de los patógenos más prevalentes en carne y productos cárnicos (Mor-Mur y Yuste, 2010).

En lo que respecta a carne producida en Uruguay, los datos disponibles indican que la contaminación con L. monocytogenes es frecuente. En este sentido, Bosilevac et al. (2007) encontraron al analizar 226 muestras de carne uruguaya que el $24 \%$ estaban contaminadas con L. monocytogenes. También se reportaron hallazgos de L. monocytogenes en carne uruguaya exportada a Rusia (European Commission, s.d.).

Debido al riesgo potencial que presentan la carne y sus productos, la industria frigorífica debe implementar distintas 
estrategias para reducir las poblaciones de patógenos en la carne cruda. La aplicación de ácidos orgánicos ha sido investigada como una posible estrategia para reducir los niveles bacterianos en carne (Rajkovic, et al., 2010).

El ácido láctico, que posee efectos bacteriostáticos y bactericidas, fue aprobado principalmente como estrategia para disminuir la contaminación por Escherichia coli O157:H7 y Salmonella. Mientras que Estados Unidos permitió su uso en carne desde 1999 (Koohmaraie, et al., 2005), la Unión Europea (UE) lo aprobó recién en 2013 (Unión Europea, 2013). Actualmente, en muchos países se aplica en establecimientos frigoríficos de manera rutinaria para reducir la contaminación bacteriana.

El Reglamento de la UE establece un rango permitido de concentración de la solución de ácido láctico de entre 2 y $5 \%$, y $2 \%$ es la concentración más utilizada en la industria (Dormedy, et al., 2000). Cuando se usa entre 2 y $4 \%$, reduce el número de E. coli O157:H7, S. typhimurium (Gill y Badoni, 2004; Yoder, et al., 2012) y L. monocytogenes (Theron y Lues, 2007; Byelashov, et al., 2010). También se ha descrito para L. monocytogenes un efecto de inhibición sobre la cepa L. monocytogenes Scott A sinérgico entre el envasado al vacío y la aplicación de ácido láctico (Ariyapitipun, et al., 2000). Sobre la carne envasada al vacío proliferan bacterias ácido lácticas que pueden ejercer efecto bactericida sobre L. monocytogenes mediante la producción de ácido láctico y bacteriocinas (Vignolo, et al., 2012).

El mecanismo de acción del ácido láctico depende de la capacidad del ácido no disociado para penetrar a través de la membrana celular y disociarse dentro de la bacteria, causando una disminución en el $\mathrm{pH}$ interno que puede interrumpir la producción de ATP, la síntesis de ARN, la replicación del ADN y el crecimiento celular (Rajkovic, et al., 2010). Algunas cepas de L. monocytogenes tienen la habilidad de adaptarse y persistir en plantas de procesamiento de alimentos (Ferreira, et al., 2014). Esta persistencia puede explicarse por la capacidad de formar biofilms y por la tolerancia a los distintos sanitizantes y estrategias de control como el $\mathrm{pH}$, temperatura y estrés salino que se utilizan a menudo en la industria. Se ha observado heterogeneidad y resistencia a distintos tipos de estrés entre cepas (Metselaar, et al., 2013), por ello es importante estudiar el comportamiento frente al ácido láctico de cepas aisladas de la misma matriz en las mismas condiciones de procesamiento que se pretende implementar la intervención.

Los cortes cárnicos de mayor valor se comercializan envasados al vacío con una vida útil de hasta dos meses si son conservados a $4{ }^{\circ} \mathrm{C}$ (García, et al., 2015), y debe garantizarse su inocuidad durante toda su vida útil. Por ello, se espera que el ácido láctico controle el crecimiento de L. monocytogenes en el sistema carne envasada al vacío. Por consiguiente, el objetivo de este trabajo fue aislar cepas de L. monocytogenes presentes en establecimientos frigoríficos nacionales y estudiar el efecto del ácido láctico sobre su crecimiento en carne envasada al vacío y las implicancias de su aplicación sobre la inocuidad del producto durante su vida útil.

\section{Materiales y Métodos}

\section{Muestreos}

Las muestras fueron tomadas en dos establecimientos frigoríficos (F1 y F2) de Uruguay en dos visitas a cada frigorífico durante julio y agosto. Estos frigoríficos no estaban utilizan- do la aplicación de ácido láctico sobre carcasa. Se realizó un muestreo dirigido, se tomaron muestras de superficie de 12 medias reses antes de ingresar a cámaras de maduración, y se tomaron 10 muestras de carne en diferentes puntos de la cinta transportadora de la línea de desosado de los cortes del trasero.

Las muestras de superficie de las medias reses se realizaron utilizando esponjas estériles (Whirl-Pak') previamente hidratadas con $10 \mathrm{~mL}$ de buffer Butterfield. Se utilizó una esponja por cada media res, y la superficie total muestreada fue de aproximadamente $8000 \mathrm{~cm}^{2}\left(4000 \mathrm{~cm}^{2}\right.$ del trasero y $4000 \mathrm{~cm}^{2}$ del delantero de una misma media res) como lo reporta Arthur (2004). El muestreo se realizó haciendo trazos verticales con la esponja de arriba hacia abajo y horizontales de izquierda a derecha. La esponja se volteó en el pasaje de los trazos horizontales a verticales. Para las muestras de carne se tomaron asépticamente 100 gramos de 10 cortes seleccionados al azar y se colocaron en bolsas estériles.

Las esponjas y las muestras de carne se conservaron refrigeradas y se trasladaron hacia el laboratorio para su análisis.

\section{Aislamiento de Listeria spp.}

Los aislamientos de Listeria spp. se realizaron directamente de las esponjas para el caso de las muestras tomadas de la superficie de las medias reses, mientras que para la carne se tomaron 10 gramos de cada muestra. Esponjas y carne se colocaron individualmente en bolsas estériles para stomacher con $90 \mathrm{~mL}$ de medio Half Fraser (Oxoid), con suplemento Half Fraser SR0166 (Thermo) y se incubaron a $30^{\circ} \mathrm{C}$ durante $24 \pm 3$ horas. Posteriormente, se trasfirieron $0,1 \mathrm{~mL}$ de los cultivos a $10 \mathrm{~mL}$ de medio de enriquecimiento secundario Fraser (Oxoid), con agregado de suplemento Fraser SR0156 (Thermo) y se incubaron a $37{ }^{\circ} \mathrm{C}$ durante $48 \pm 3$ horas. Luego, se sembró por estrías una ansada sobre placas de agar Palcam con agregado del suplemento selectivo para Palcam SR0150 (Thermo) y se incubaron 48 horas a $37^{\circ} \mathrm{C}$. Las colonias características de Listeria spp. en agar Palcam presentan aproximadamente $2 \mathrm{~mm}$ de diámetro y una coloración verde-grisácea con halo marrón oscuro-negro. Las colonias con esta morfología se aislaron sucesivamente en placas con agar tripticasa de soja (TSA) (Oxoid) suplementado con $0,6 \%$ de extracto de levadura (YE) (Oxoid) con el fin de obtener cultivos puros, y se incubaron 18 horas a $37^{\circ} \mathrm{C}$. Para su conservación, se repicaron de una colonia a un tubo de TSA-YE inclinado, y se incubaron 18-20 horas a $37^{\circ} \mathrm{C}$. Luego se mantuvieron refrigeradas $\left(4 \pm 1^{\circ} \mathrm{C}\right)$ hasta el momento de su uso.

\section{Identificación según propiedades bioquímicas}

Se caracterizaron los aislamientos mediante tinción de Gram, actividad catalasa y galerías API. Para realizar la tinción de Gram y la prueba de catalasa se partió de una colonia de un cultivo joven (18-24 horas) de placas de TSA-YE. Para el sistema de galerías API Listeria, se suspendieron tres colonias aisladas de cultivos jóvenes (18-24 horas) en una ampolla de API Suspension Medium ( $2 \mathrm{~mL}$ ) y se ajustó a una suspensión igual a 1 de McFarland. Se sembraron $50 \mu \mathrm{L}$ con la suspensión en todos los tubos de la galería, excepto en el ensayo DIM, que se sembraron $100 \mu \mathrm{L}$ según instrucciones del fabricante. Se incubó $18-24$ horas a $36 \pm 2{ }^{\circ} \mathrm{C}$ en atmósfera aerobia. 


\section{Identificación molecular}

Se realizó la confirmación de género y especie de los aislamientos a nivel molecular usando una PCR multiplex a tiempo final y una PCR a tiempo real. Para la extracción de ADN genómico de todos los aislamientos de Listeria se utilizó el kit Mericon ${ }^{\mathrm{TM}}$ DNA Bacteria Plus Kit (Qiagen), a partir de 1 $\mathrm{mL}$ de cultivo en medio TSB con extracto de levadura incubados a $37^{\circ} \mathrm{C}$ durante 18 horas. La PCR múltiplex utilizada fue una modificación de la reportada por Bubert et al. (1999). Se utilizaron los cebadores, MonoA(F), Ino2(F) y Siwi2(F) y Lis1B(R) (Bubert, et al., 1999) y Gral(F) (Acquistapace, 2015). Los cebadores fueron sintetizados por Macrogen Inc. (Seúl, Corea). La reacción consistió en 30 ciclos: $95^{\circ} \mathrm{C}$ durante 15 segundos, $58{ }^{\circ} \mathrm{C}$ durante 30 segundos, y $72{ }^{\circ} \mathrm{C}$ durante 50 segundos. Se utilizó un termociclador Rotor-Gene Q. Se usó como control negativo agua miliQ estéril, como control positivo para L. innocua, la cepa de L. innocua ATCC 33090, y como control positivo para $L$. monocytogenes, la cepa de ATCC 19111. Los productos de PCR fueron visualizados mediante electroforesis en gel de agarosa al 1,2\% en buffer TAE 1X. Los productos de PCR se sembraron con buffer Loading Dye 6X (Thermo Scientific) y se utilizó el marcador de peso molecular de $1 \mathrm{~Kb}$ (Thermo Scientific).

Para la PCR a tiempo real se utilizaron los pares de cebadores prs-2(F) y prs-2-deg $(\mathrm{R})$ para identificar Listeria spp., el par hlyA-177(F) y (R) y el par hlyA-146-deg-tronc(F) y (R), ambos para identificar L. monocytogenes (Barbau-Piednoir, et al., 2013). El programa térmico para las tres reacciones consistió en: un ciclo de activación de ADN polimerasa de 5 minutos a $95^{\circ} \mathrm{C}$, seguido de 30 ciclos de amplificación de 15 segundos a $95^{\circ} \mathrm{C}$ y 1 minuto a $60^{\circ} \mathrm{C}$. Luego se realizó la curva de desnaturalización (melting) de los productos de la amplificación mediante el aumento gradual de la temperatura de 60 a $95^{\circ} \mathrm{C}$ en 20 minutos $\left( \pm 0,6^{\circ} \mathrm{C} / 20\right.$ segundos) utilizando el mismo termociclador que para la PCR multiplex. La reacción se realizó en un volumen final de $25 \mu \mathrm{L}$, con $2 \mu \mathrm{L}$ de ADN muestra, 1X Rotor-Gene TMSYBR'Green PCR MasterMix (Qiagen) y $500 \mathrm{nM}$ de cada cebador.

\section{Sensibilidad de los aislamientos frente al ácido láctico en placa}

Para evaluar la sensibilidad al ácido láctico de los aislamientos de Listeria, se determinaron la concentración mínima inhibitoria (CMI) y la concentración mínima bactericida (CMB) mediante la técnica de microdilución en caldo y posterior siembra en placas de agar Palcam con agregado del suplemento selectivo para Palcam (SR0150 Thermo) para el recuento de viables. Para ello se seleccionaron todos los aislamientos identificados como L. monocytogenes. Los inóculos se prepararon a partir de cultivos en fase exponencial, ajustando la absorbancia $(625 \mathrm{~nm})$ en un rango entre 0,08 y 0,10 equivalente al patrón 0,5 de la escala de McFarland $\left(1,5 \times 10^{8}\right.$ ufc/ $\mathrm{mL}$ ). A continuación se realizó la dilución correspondiente en buffer Butterfield estéril para alcanzar una concentración final de $1 \times 10^{6} \mathrm{ufc} / \mathrm{mL}$.

Las soluciones de ácido láctico de diferentes concentraciones se prepararon con agua destilada estéril a partir de una solución comercial de ácido láctico $85 \%$ (m/v) (Nortesur S.A., Montevideo).

Para determinar la CMI se utilizaron placas de 96 pocillos. La concentración inicial del inóculo en cada pocillo fue de
$2,5 \times 10^{6} \mathrm{ufc} / \mathrm{mL}$ y las concentraciones finales de ácido láctico en el pocillo fueron $1,2 \%, 0,7 \%, 0,4 \%, 0,3 \%, 0,2 \%, 0,1 \%$ y $0 \%$. Se realizaron controles positivos (inóculo + TSB-YE) y controles negativos (la concentración más alta de ácido láctico + TSB-YE). Las placas se incubaron a $35^{\circ} \mathrm{C}$ durante $16-20$ horas. La lectura de absorbancia de la microplaca se realizó en un lector de placas Multiskan Ex, Thermo Scientific ${ }^{\bullet}$ a 620 $\mathrm{nm}$. Se considera la concentración mínima inhibitoria (CMI) a la mínima concentración de ácido láctico en la que no se observa desarrollo bacteriano (valor de $\mathrm{OD} \leq 0,05$ ) (Branen, et al., 2004). A su vez, se midió el pH en la microplaca luego del periodo de incubación para las distintas concentraciones de ácido utilizando un pHmetro Hanna ${ }^{\circledR}$ modelo 9025c.

Para determinar la CMB se tomaron $100 \mu \mathrm{L}$ de los pocillos sin crecimiento visible de la bacteria $(O D \leq 0,05)$ y se sembraron en placas de agar Palcam con agregado del suplemento selectivo para Palcam (SR0150 Thermo). Las placas de agar Palcam se incubaron $24-48$ horas a $37^{\circ} \mathrm{C}$. Se considera la concentración mínima bactericida (CMB) a la menor concentración de ácido láctico que en placas de agar es capaz de eliminar el 99,99\% del inóculo inicial (lo que se visualiza por la ausencia de colonias en placa). Los ensayos se realizaron por triplicado para cada aislamiento seleccionado. Las diferencias entre los tratamientos se determinaron mediante ANOVA, seguido de la prueba de Tukey $(\mathrm{p}<0,05)$ utilizando el programa IBM SPSS Statistics 20.

\section{Sensibilidad de los aislamientos frente al ácido láctico en carne}

Para evaluar la sensibilidad al ácido láctico en carne se eligió el aislado de L. monocytogenes L100A1. La carne usada correspondió a un corte de bife angosto (músculo largo dorsal) envasado al vacío adquirido en una carnicería de Montevideo, del cual se cortaron trozos de 10 gramos (5 $\mathrm{cm} \times 5 \mathrm{~cm}$ ). Luego se colocaron sobre una superficie limpia, previamente expuesta a radiación UV durante 20 minutos y se inocularon asépticamente con $1 \mathrm{~mL}$ de L100A1 de $1 \times 10^{6}$ $\mathrm{ufc} / \mathrm{mL}$ (preparado como se indica en los ensayos de sensibilidad de los aislamientos frente al ácido láctico en placa). Se dejaron 20 minutos a temperatura ambiente $\left(22^{\circ} \mathrm{C}\right)$ para permitir la fijación del inóculo a la superficie de cada trozo de carne (Carpenter, et al., 2011) previo a aplicar el tratamiento de ácido láctico.

\section{Ensayo 1}

Seis trozos de 10 gramos de carne se inocularon con $1 \mathrm{~mL}$ de un cultivo $1 \times 10^{6} \mathrm{ufc} / \mathrm{mL}$ del aislado L100A 1 y se trataron por duplicado con ácido láctico al 0,2,5\% y $5 \%$ en una relación de $0,03 \mathrm{~mL}$ de ácido por $\mathrm{cm}^{2}$ de carne (Youssef, et al., 2012). Luego de 20 minutos, los trozos de carne tratados se envasaron al vacío individualmente en bolsas Cryovac T7335B, utilizando una envasadora SAMMIC modelo V-410SGI. Un grupo de muestras se analizó inmediatamente (tiempo cero) y el segundo grupo fue almacenado a $4{ }^{\circ} \mathrm{C}$ y analizado a los 14 días. A su vez, se prepararon seis trozos de carne adicionales (uno por cada concentración de ácido láctico) sobre los cuales se midió y registró el $\mathrm{pH}$ superficial de la carne para ambos tiempos, utilizando un pHmetro Hanna ${ }^{\circledR}$ modelo 9025 c con un electrodo de superficie.

Para el análisis de cada muestra se transfirió asépticamente el trozo de carne a una bolsa estéril para stomacher y se 
homogeneizó con $90 \mathrm{~mL}$ de buffer Butterfield en Stomacher Seward 400C LabBlenders, a $230 \mathrm{rpm}$ durante 2 minutos. Se plaquearon $100 \mu \mathrm{L}$ de ese caldo en placas de agar Palcam con agregado del suplemento selectivo para Palcam (SR0150 Thermo), y se incubaron $24-48$ horas a $37^{\circ} \mathrm{C}$. Se realizaron los recuentos de L. monocytogenes y los resultados se expresaron como log ufc/g de carne. Las diferencias entre los tratamientos se determinaron mediante ANOVA, seguido de la prueba de Tukey con un nivel de significación del $5 \%(\mathrm{p}<0,05)$ utilizando el programa IBM SPSS Statistics 20.

\section{Ensayo 2}

Quince trozos de 10 gramos de carne se inocularon con $1 \mathrm{~mL}$ de $1 \times 10^{6} \mathrm{ufc} / \mathrm{mL}$ del aislado L100A1, y se separaron en tres subgrupos que se trataron con diferentes concentraciones de ácido láctico $(5 \%, 2,5 \%$ y $0 \%)$. Todas las muestras se envasaron individualmente al vacío y se almacenaron a $4{ }^{\circ} \mathrm{C}$. Los recuentos de $L$. monocytogenes se determinaron a la semana $1,2,3,5$ y 8 , como se describió para el ensayo 1. También se realizó recuento de bacterias ácido lácticas (BALs) a las muestras tratadas con $5 \%$ y sin ácido láctico en medio MRS agar mediante siembra incorporada. Las placas se incubaron a $25^{\circ} \mathrm{C}$ durante 72 horas. Se realizaron dos ensayos independientes y los resultados de los recuentos se analizaron como se mencionó en el ensayo 1.

\section{Resultados y Discusión}

\section{Búsqueda de Listeria spp.}

Del muestreo realizado sobre la superficie de las medias reses antes de la cámara de maduración, no se recuperó Listeria spp., pero sí se recuperó de todas las muestras de carne tomadas en la sala de desosado de ambos establecimientos frigoríficos. A pesar de haber analizado un número bajo de muestras, los resultados concuerdan con lo reportado por Nychas et al. (2008) y McLauchlin (2004): la contaminación por Listeria spp. se debe principalmente a la contaminación que se produce durante la manipulación por cepas presentes en ambiente y equipos.

Por otro lado, el hecho de que se haya recuperado Listeria de todas las muestras de carne analizadas en ambos establecimientos se debe a que las muestras se tomaron en sitios de alto riesgo de contaminación y a la existencia de una alta prevalencia. En este sentido, Bosilevac et al. (2007) determinaron en carne uruguaya exportada a Estados Unidos una prevalencia de Listeria del 29\%, es decir, 66 de las 226 muestras analizadas contenían al menos una especie.

En cuanto a las características de los aislamientos, todos fueron Gram positivos y catalasa positivos, características propias del género Listeria. Los amplicones obtenidos utilizando la PCR multiplex (Bubert, et al., 1999) correspondieron a los tamaños esperados para L. innocua (870 bp) y para L. monocytogenes $(660 \mathrm{pb})$. No se observaron amplicones correspondientes a las especies $L$. seliigeri, $L$. ivanovii, $L$. welshimeri y L. grayi. Los resultados del método molecular coincidieron con la identificación mediante galerías API. De los 35 aislamientos obtenidos, 29 correspondieron a $L$. innocua y 6 a L. monocytogenes. Todos los aislados de $L$. monocytogenes estudiados presentaron únicamente el perfil API 6510. Según Ballesteros (2009), los perfiles numéricos más frecuentes en galerías API de L. monocytogenes aisladas de alimentos son 6510 y 6110 .

A los seis aislamientos identificados como L. monocytogenes por PCR multiplex y galerías API se les confirmó su identidad determinando la presencia de los genes prs y $h l y A$ (Gráfico 1A y Gráfico 1B). A su vez, utilizando el par de cebadores $h l y A$-146-deg-tronc(F) y hlyA-146(R) se observa que las curvas de disociación de los amplicones correspondientes a los seis aislamientos se separan en dos grupos (Gráfico 1C). Barbau-Piednoir et al. (2013) reportaron que los serotipos $1 / 2 \mathrm{a}, 1 / 2 \mathrm{c}, 3 \mathrm{a}, 3 \mathrm{c}, 4 \mathrm{a}, 4 \mathrm{~d}$ y $4 \mathrm{e}$ presentan una temperatura de melting $(\mathrm{Tm})$ de entre $73,5-74^{\circ} \mathrm{C}$, mientras que los serotipos $1 / 2 \mathrm{~b}, 3 \mathrm{~b}, 4 \mathrm{~b}$ y $4 \mathrm{c}$ presentan una Tm de $75^{\circ} \mathrm{C}$. En este estudio, los aislados L100A1, L100A2 y L100D3 presentaron una Tm de $79^{\circ} \mathrm{C}$, mientras que L101B1, L101B2, L101E3 y la ATCC 19111 una Tm de 78,2 ${ }^{\circ} \mathrm{C}$. El control positivo ATCC 19111
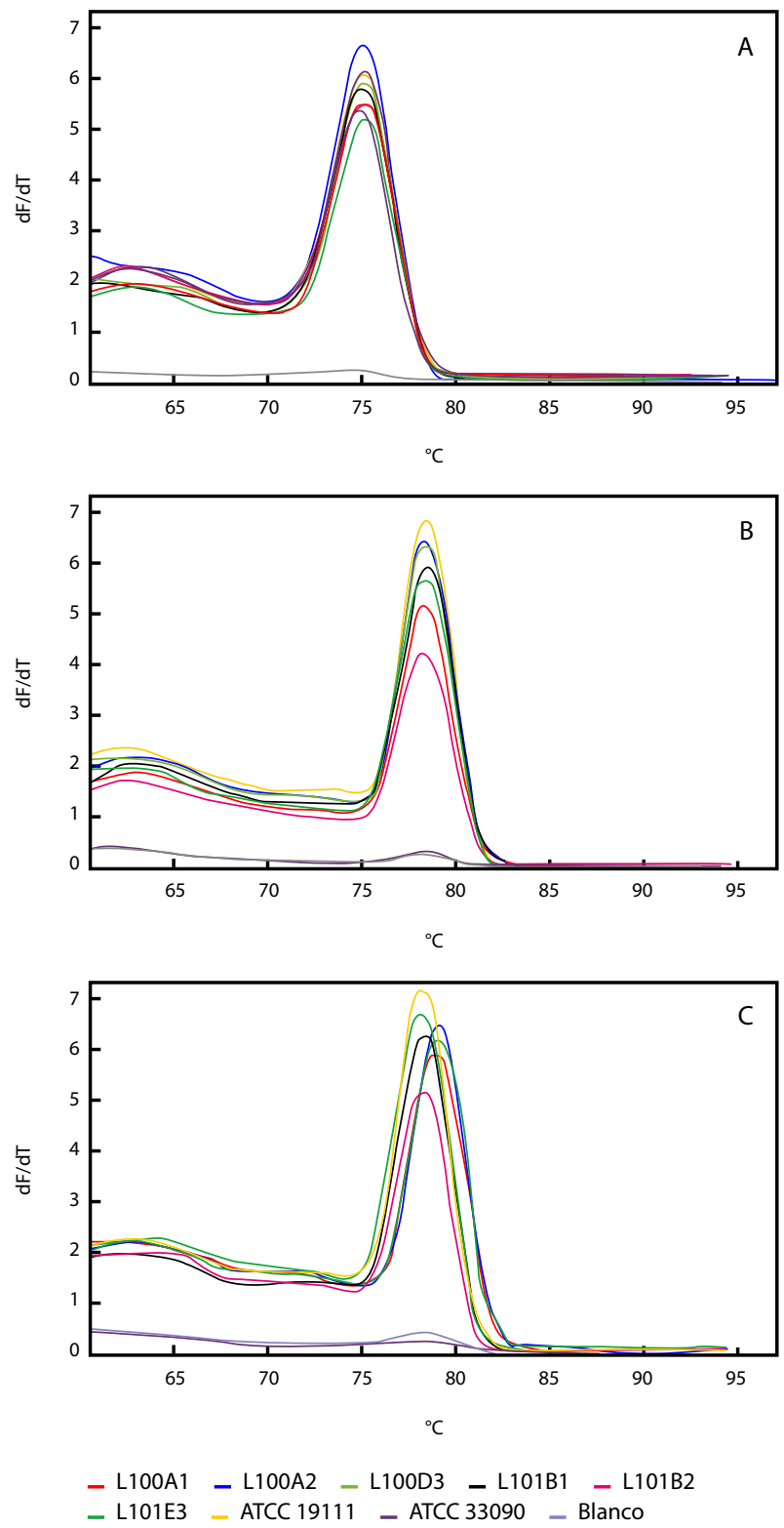

Gráfico 1. Curvas de disociación de qPCR obtenidas con $\mathrm{SYBR}^{\oplus}$ Green. Los diferentes ensayos de qPCR son A:prs-2deg, B:hlyA-177 y C:hlyA-146-deg-tronc. 
pertenece al serotipo 1/2a, en coincidencia con la presencia de esta cepa en el grupo de menor Tm. Por tanto, se puede inferir que se encontraron por lo menos dos serotipos distintos de L. monocytogenes. En línea con este resultado, Bosilevac et al. (2007) reportaron la existencia de distintos serotipos en las cepas de L. monocytogenes aisladas de carne uruguaya: el $5 \%$ pertenecían al serotipo $1 / 2 \mathrm{a}, 28 \%$ al $1 / 2 \mathrm{~b}, 29 \%$ al $1 / 2$ c y el $38 \%$ al 4 b. A su vez, Braga (2017) también encontró que los serotipos de mayor frecuencia en alimentos uruguayos son los serotipos $1 / 2$ b y 4 b, seguidos de los serotipos $1 / 2$ a y $1 / 2$ c.

\section{Sensibilidad} al ácido láctico en placa

Todos los aislados de L. monocytogenes (6) expuestos al ácido láctico presentaron el mismo patrón de inhibición de crecimiento (Gráfico 2). La mínima concentración de ácido láctico en el pocillo a partir de la cual no se observó crecimiento fue de $0,3 \%$. La siembra en placas de agar Palcam de los cultivos provenientes de los pocillos de la microplaca en los que hubo inhibición de crecimiento mostró que a partir de una concentración de $0,7 \%$ ya no se recuperaron colonias viables (Tabla 1). Valores similares fueron reportados por Oh (1993), quien observó que una concentración de 0,25\% de ácido láctico inhibe el crecimiento de L. monocytogenes en caldo de TSB-YE a $35^{\circ} \mathrm{C}$. La inhibición del crecimiento de Listeria por ácido láctico ha sido ampliamente reportada y se atribuye a dos factores: al descenso del $\mathrm{pH}$ en el medio ambiente y a la capacidad de la forma no disociada de atravesar la membrana celular e interferir con el funcionamiento celular (Rajkovic, et al., 2010).

Para la condición ensayada con $0,7 \%$ de ácido láctico, donde no se observaron colonias viables, el $\mathrm{pH}$ fue de 4,5 , acorde a los resultados de Sorrels (1989), que indican que el ácido láctico es más efectivo en inhibir el desarrollo de L. monocytogenes cuando alcanza valores de $\mathrm{pH}$ de entre 4,5 a 4,6. Los valores definidos como CMI y CMB para L100A1 se muestran en el Gráfico 3 y en la Tabla 1, respectivamente. El aislado L100A1 se eligió para continuar con los estudios en carne.

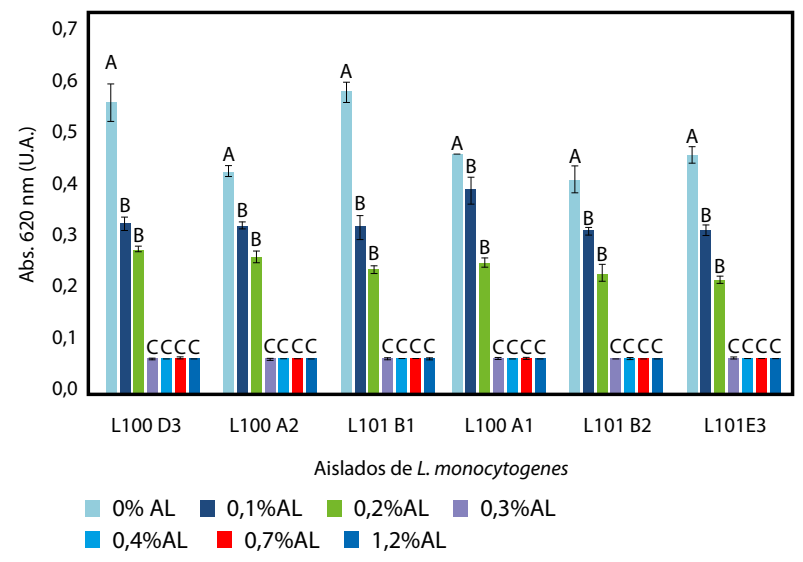

Gráfico 2. Sensibilidad de los aislamientos de $L$. monocytogenes frente a diferentes concentraciones de ácido láctico. Las barras de error representan el error estándar de la media de tres medidas independientes. Para cada aislamiento letras distintas indican diferencias significativas $(\mathrm{p}<0,05)$.

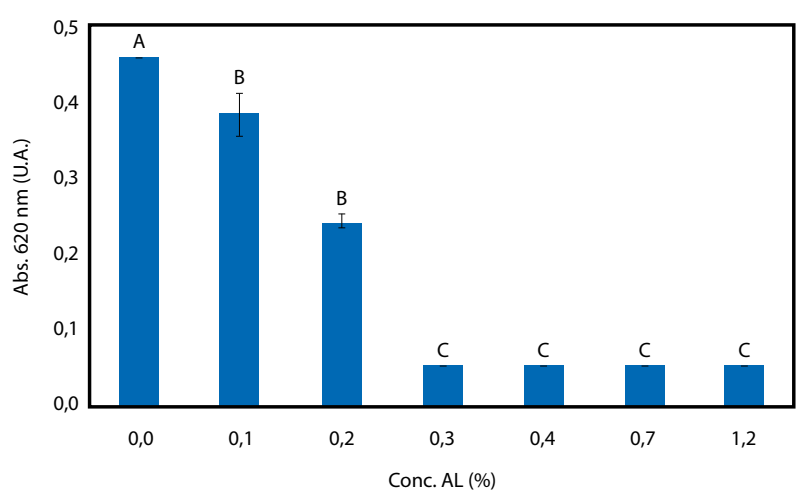

Gráfico 3. Curvas de inhibición en TSB-YE en función de la concentración de ácido láctico (AL) para L100A1 ( $L$. monocytogenes). Las barras de error representan el error estándar de la media de tres medidas independientes. Letras distintas indican diferencias significativas $(\mathrm{p}<0,05)$.

\begin{tabular}{|c|c|c|c|c|c|}
\hline \multirow{2}{*}{ Aislado } & \multicolumn{5}{|c|}{ Concentración de ácido láctico (\%) } \\
\cline { 2 - 6 } & $\mathbf{1 , 2}$ & $\mathbf{0 , 7}$ & $\mathbf{0 , 4}$ & $\mathbf{0 , 3}$ & $\mathbf{0 , 2}$ \\
\hline L100A1 & - & - & + & + & + \\
\hline
\end{tabular}

Tabla 1. Recuperación de células viables en placas de agar Palcam provenientes del cultivo de la microplaca para L100A1. (-) ausencia de crecimiento bacteriano visible en placas $(+)$ crecimiento bacteriano visible en placas.

\section{Efectos de la aplicación del ácido láctico sobre L100A1 en carne envasada al vacío}

\section{pH superficial}

La aplicación de ácido láctico reduce el $\mathrm{pH}$ de la superficie de la carne, que llega a 5,1 y 4,8 para los tratamientos de 2,5 y $5 \%$ de ácido láctico. La reducción es significativa $(\mathrm{p}<0,05)$ cuando se aplica ácido láctico al 5\% (Tabla 2). A los 14 días no se observaron cambios significativos en los valores de $\mathrm{pH}$ y se mantiene la diferencia entre las muestras tratadas y no tratadas. Esta diferencia en $\mathrm{pH}$ debida a la aplicación de ácido láctico en carnes envasadas al vacío y conservadas a $4{ }^{\circ} \mathrm{C}$ fue reportada por Ariyapitipun et al. (2000), quienes observaron

\begin{tabular}{|c|c|c|c|c|}
\hline \multirow{2}{*}{$\begin{array}{c}\text { Ácido } \\
\text { láctico } \\
(\%)\end{array}$} & \multicolumn{2}{|c|}{ Tiempo cero } & \multicolumn{2}{|c|}{14 días } \\
\cline { 2 - 5 } & $\begin{array}{c}\mathrm{pH} \\
\text { promedio }\end{array}$ & DS & $\begin{array}{c}\mathrm{pH} \\
\text { promedio }\end{array}$ & DS \\
\hline 0 & $5,43^{\mathrm{A}}$ & 0,03 & $5,37^{\mathrm{A}}$ & 0,04 \\
2,5 & $5,00^{\mathrm{A}, \mathrm{B}}$ & 0,36 & $5,09^{\mathrm{A}, \mathrm{B}}$ & 0,07 \\
5 & $4,76^{\mathrm{B}}$ & 0,23 & $4,83^{\mathrm{B}}$ & 0,13 \\
\hline
\end{tabular}

Tabla 2. Valores de $\mathrm{pH}$ superficial promedio de los trozos de carne medidos a tiempo 0 y a los 14 días de envasado. DS: desviación estándar. Para cada tiempo letras distintas en columnas indican diferencias significativas $(\mathrm{p}<0,05)$. 
que las diferencias de $\mathrm{pH}$ entre tratamientos seguían siendo significativas hasta los 21 días. Luego de este tiempo ya no se percibían diferencias, debido a que el $\mathrm{pH}$ de las muestras tratadas había aumentado, posiblemente por la penetración del ácido láctico en la carne y a la neutralización del ácido por las proteínas de la carne (Woolthuis, et al., 1985).

\section{Efecto bactericida y bacteriostático del ácido láctico sobre L100A1 en carne}

La aplicación de ácido láctico en carne tiene un efecto bactericida inmediato sobre L. monocytogenes L100A1. Para las dos concentraciones de ácido láctico ensayadas a tiempo cero, la mayor disminución en los recuentos de L. monocytogenes se produjo con $5 \%$ de ácido láctico. La aplicación de ácido láctico al 2,5\% redujo en 1,1 log, y al 5\% la reducción fue de $1,4 \mathrm{log}$, significativa con respecto al control. Varios estudios mostraron el efecto bactericida del ácido láctico sobre $L$. monocytogenes (Gráfico 4). En este sentido, DeGeer et al. (2016) obtuvieron reducciones similares de L. monocytogenes en carne fresca tratada con soluciones de 2 y $4 \%, 0,85 \mathrm{log}$ ufc/ $\mathrm{cm}^{2}$ y $1,3 \mathrm{log}$, respectivamente, mientras que Ariyapitipun et al. (2000) lograron una reducción de $1,56 \mathrm{log} \mathrm{ufc} / \mathrm{cm}^{2}$ aplicando una solución de ácido láctico al $2 \%$. Las diferencias en la magnitud de la reducción entre los diferentes estudios pueden deberse, entre otros factores, a la variación entre las cepas utilizadas y al modo de aplicación de las soluciones de ácido láctico. En este estudio la cepa usada, L100A1, fue aislada de ambiente frigorífico luego de haber sufrido diferentes tipos de estrés que, según Skandamis (2008), pueden afectar la tolerancia en medios ácidos. Por otro lado, en este estudio el ácido láctico fue aplicado por aspersión, mientras que en los trabajos de DeGeer et al. (2016) y Ariyapitipun et al. (2000) fue por inmersión. Es posible que la aplicación de ácido láctico por inmersión logre obtener una mayor cantidad de ácido sobre la superficie de la carne.

A los 14 días, las muestras envasadas al vacío y conservadas a $4{ }^{\circ} \mathrm{C}$ presentaron un descenso no significativo en los recuentos de L100A 1 para las muestras sin tratar y significativo

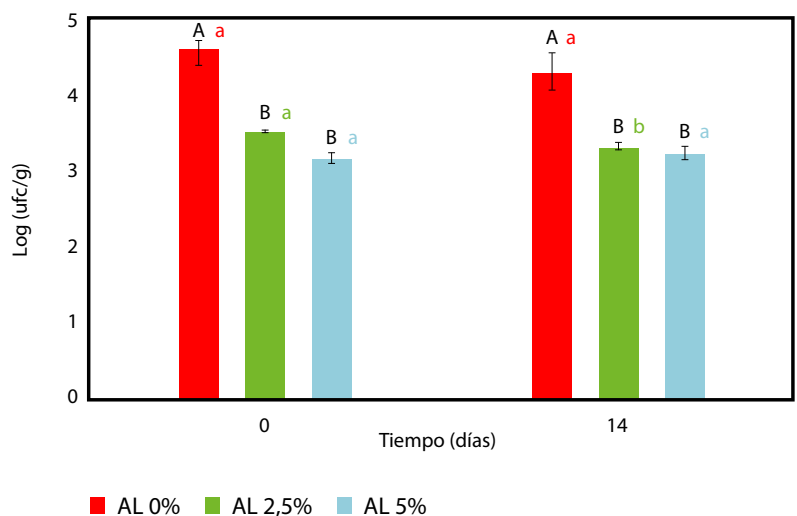

Gráfico 4. Recuentos promedio de L. monocytogenes L100A1 a tiempo 0 y a los 14 días en carnes con 5\%, 2,5\% y sin ácido láctico $(\mathrm{AL})$. Las barras de error representan el error estándar de la media de dos medidas independientes. A,B Diferentes letras indican diferencias significativas $(\mathrm{p}<0,05)$ en un mismo tiempo para diferentes tratamientos. a,b Diferentes letras indican diferencias significativas $(p<0,05)$ para un mismo tratamiento en diferentes tiempos. $(\mathrm{p}<0,05)$ para las muestras tratadas con $2,5 \%$ de ácido láctico (Gráfico 4) con respecto a su valor al tiempo 0. Para las muestras tratadas con $5 \%$ de ácido láctico no hubo cambios significativos al final de los 14 días.

Este efecto bacteriostático de la aplicación de ácido láctico en condiciones de envasado al vacío y conservación a $4{ }^{\circ} \mathrm{C}$ se estudió durante ocho semanas, tiempo máximo de vida útil de la carne envasada al vacío y conservada a $4{ }^{\circ} \mathrm{C}$ (García, et al., 2015).

Durante este tiempo el patrón de crecimiento de $L$. monocytogenes L100A1 en las muestras no tratadas mostró que el envasado al vacío impidió el crecimiento de este organismo (Gráfico 5). Su crecimiento fue significativamente inhibido $(p<0,05)$ hasta las ocho semanas. En este tiempo de almacenamiento, el número de células se redujo en aproximadamente $1,4 \log$ ufc/g. Por otro lado, en las muestras tratadas con ácido láctico $2,5 \%$ se observó una reducción más pronunciada en el tiempo que en las muestras control, el número de L100A1 se redujo 1,6 log en cinco semanas, en línea con el efecto sinérgico previamente reportado por Ariyapitipun et al. (2000) entre el envasado al vacío, la baja temperatura y la aspersión con ácido láctico al $2,5 \%$. Sin embargo, en las muestras tratadas con 5\% de ácido láctico, el número de L100A1 se mantuvo constante durante las ocho semanas (Gráfico 5).

En la carne envasada al vacío y conservada a $4{ }^{\circ} \mathrm{C}$ se generan condiciones que inhiben el crecimiento de Listeria: $\mathrm{pH}$ 5,4 o inferior, baja temperatura y anaerobiosis. Además, en estas condiciones proliferan las bacterias ácido lácticas naturales de la carne, que producen ácidos orgánicos y bacteriocinas (Castellano, et al., 2008; Vignolo, et al., 2012) e inhiben el crecimiento de Listeria (Guerrieri, et al., 2009; Chaillou, et al., 2005; Holzapfel, et al., 1995; Jones, et al., 2004). En este trabajo, en paralelo a la disminución de Listeria, la población de bacterias ácido lácticas aumentó, tanto en las muestras tratadas como en las no tratadas con ácido láctico, desde 2,7 log ufc/g hasta valores por encima de 7 log ufc/g en cinco semanas (Gráfico 6), lo cual explicaría parte del efecto bacteriostático observado para las muestras control y las tratadas con 2,5\% de ácido láctico. Sin embargo,

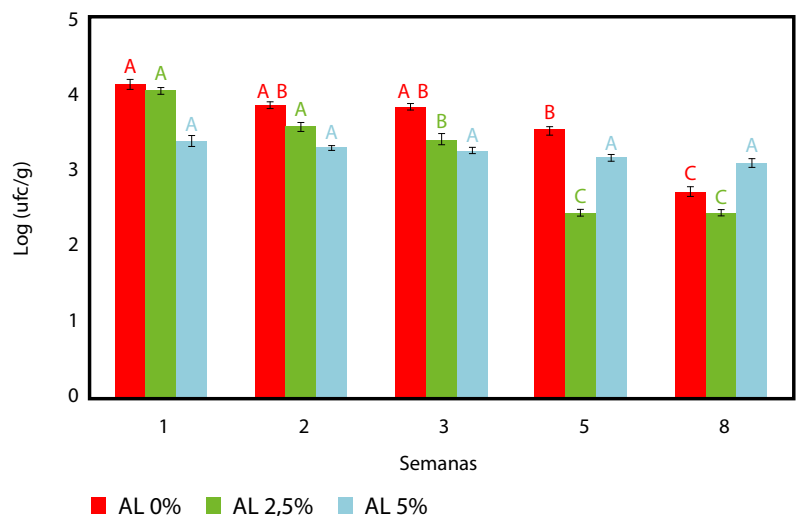

Gráfico 5. Recuentos promedio de L. monocytogenes L100A1 durante ocho semanas para carnes tratadas con $5 \%, 2,5 \%$ y sin ácido láctico (AL). Las barras de error representan el error estándar de la media de dos medidas independientes. ${ }^{\mathbf{A}, \mathbf{B}, \mathbf{C}}$ Diferentes letras indican diferencias significativas $(p<0,05)$ en el tiempo para un mismo tratamiento. 


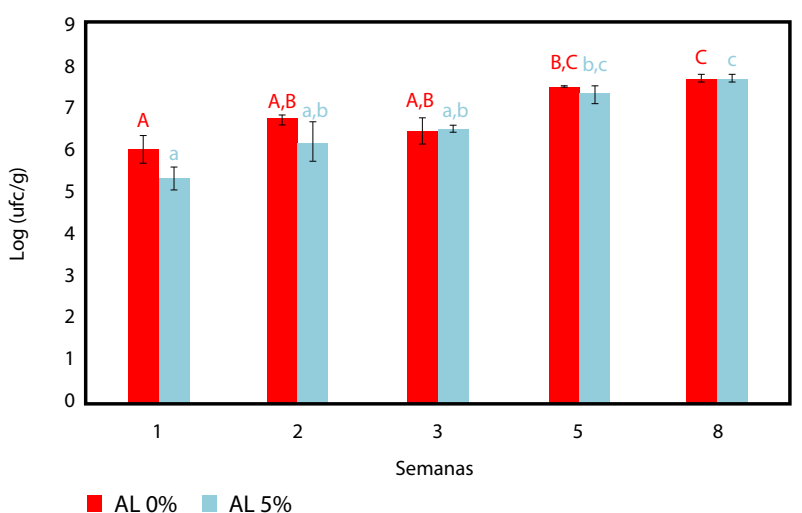

Gráfico 6. Recuentos de bacterias ácido lácticas (log ufc/g) durante ocho semanas en muestras tratadas con $5 \%$ y sin ácido láctico $(\mathrm{AL})$. Las barras de error representan el error estándar de la media de dos medidas independientes. A,B,C Diferentes letras indican diferencias significativas $(p<0,05)$ en el tiempo para las muestras sin AL. $\mathbf{a}, \mathbf{b}, \mathbf{c}$ Diferentes letras indican diferencias significativas $(\mathrm{p}<0,05)$ en el tiempo para las muestras con $5 \%$ de AL.

y a pesar de estar en las mismas condiciones, las bacterias que sobrevivieron a la aplicación inicial de ácido láctico al 5\% aparentan ser más resistentes al estrés generado por el envasado al vacío y las bajas temperaturas. En línea con esta observación, la combinación de estrés subletales puede afectar la tolerancia de L. monocytogenes a medios ácidos o tratamientos térmicos posteriores (Skandamis, et al., 2008), lo que presenta un riesgo mayor en aquellos productos elaborados a partir de carne que no usan la cocción como estrategia de descontaminación.

\section{Conclusiones}

La estrategia planteada de muestreo permitió aislar Listeria monocytogenes de muestras de carne tomadas en establecimientos frigoríficos nacionales. De los aislamientos estudiados hasta el momento, se evidencia la presencia de más de un serotipo de L. monocytogenes. Los aislamientos fueron sensibles al ácido láctico, tanto in vitro como en el sistema carne envasada al vacío y conservada a $4{ }^{\circ} \mathrm{C}$. En este sistema se observó un efecto combinado entre el ácido láctico al 2,5\% aplicado sobre la carne y el envasado al vacío. Sin embargo, a concentraciones de ácido láctico de 5\% se observó una mayor resistencia a las condiciones generadas por el envasado al vacío. Se debe estudiar con mayor profundidad tanto la incidencia sobre la sobrevivencia de L. monocytogenes de la concentración del ácido láctico aplicado sobre la carne antes de envasarla a vacío como también el comportamiento, en esta situación, de los distintos aislamientos que persisten en el ambiente frigorífico nacional.

\section{Reconocimientos}

Los autores agradecen el apoyo financiero brindado por el Proyecto INNOVA 2, Cooperación Europea - ANII y a los dos establecimientos frigoríficos por toda su colaboración y por permitirnos el ingreso a sus instalaciones.

\section{Referencias}

Acquistapace, M.J., 2015. Efecto de la aplicación de ácido láctico sobre el crecimiento de Listeria spp. aisladas de establecimientos frigoríficos nacionales. Montevideo: Facultad de Ciencias. (Tesina de Grado).

Ariyapitipun T., Mustapha A. y Clarke A. D., 2000. Survival of Listeria monocytogenes Scott A on vacuum-packaged raw beef treated with polylactic acid, lactic acid, and nisin. En: Journal of Food Protection, 63(1), pp.131-136.

Arthur, T. M., Bosilevac, J. M., Nou, X., Shackelford, S. D., Wheeler, T. L., Kent, M. P., Jaroni, D., Pauling, B., Allen, D. M. y Koohmaraie, M., 2004. Escherichia coli O157 prevalence and enumeration of aerobic bacteria, Enterobacteriaceae, and Escherichia coli $\mathrm{O} 157$ at various steps in commercial beef processing plants. En: Journal of Food Protection, 67, pp.658-665.

Ballesteros, L., 2009. Caracterización fenotípica y genotípica de cepas de listeria monocytogenes aisladas de vegetales congelados. Valencia: Universidad Politécnica de Valencia. (Tesis de Maestría).

Barbau-Piednoir, E., Botteldoorn, N., Yde, M.,Mahillon, J. y Roosens, N.H., 2013. Development and validation of qualitative SYBR $^{\circ}$ Green Real-Time PCR for detection and discrimination of Listeria spp. and Listeria monocytogenes. En: Applied Microbiology and Biotechnology, 97, pp.4021-4037.

Bosilevac, J. M., Guerini, M. N., Brichta-Harhay, D. M., Arthur, T. M. y Koohmaraie, M., 2007. Microbiological characterization of imported and domestic boneless beef trim used for ground beef. En: Journal of Food Protection, 70(2), pp.440-449.

Braga, V., Vázquez, S., Vico, V., Pastorino, V., Mota, M. I., Legnani, M., Schelotto, F., Lancibidad, G. y Varela, G., 2017. Prevalence and serotype distribution of Listeria monocytogenes isolated from foods in Montevideo-Uruguay. En: Brazilian Journal of Microbiology, 48(8), pp.689-694.

Branen, J. K. y Michael Davidson, P., 2004. Enhancement of nisin, lysozyme, and monolaurin antimicrobial activities by ethylenediaminetetraacetic acid and lactoferrin. En: International Journal of Food Microbiology, 90, pp.63-74.

Bubert, A., Hein, I., Rauch, M., Lehner, A., Yoon, B., Goebel, W. y Wagner, M., 1999. Detection and Differentiation of Listeria spp. by a Single Reaction Based on Multiplex PCR. En: Applied and Environmental Microbiology, 65(10), pp.4688-4692.

Buchanan, R. L., Gorris, L. G. M., Hayman, M. M., Jackson, T. C. y Whiting, R. C., 2017. A review of Listeria monocytogenes: An update on outbreaks, virulence, doseresponse, ecology, and risk assessments. En: Food Control, 75, pp.1-13.

Byelashov, O. A., Daskalov, H., Geornaras, I., Kendall, P. A., Belk, K. E., Scanga, J. A., Smith, G. C. y Sofos, J. N., 2010. Reduction of Listeria monocytogenes on frankfurters treated with lactic acid solutions of various temperatures. En: Food Microbiology, 27, pp.783-790.

Carpenter, C. E., Smith, J. V. y Broadbent, J. R., 2011. Efficacy of washing meat surfaces with $2 \%$ levulinic, acetic, or lactic acid for pathogen decontamination and residual growth inhibition. En: Meat Science, 88(2), pp.256-260.

Castellano, P., Belfiore, C., Fadda, S. y Vignolo, G., 2008. A review of bacterogenic lactic acid bacteria used as bioprotective cultures in fresh meat produced in Argentina. En: Meat Science, 79, pp.483-499. 
CDC, 2014. CDC national health report: Leading causes of morbidity and mortality and associated behavioral risk and protective factors - United States, 2005 -2013 [En línea]. Atlanta: CDC. [Consulta: 7 de marzo de 2018]. Disponible en:https://stacks.cdc.gov/view/cdc/25809.

Chaillou, S., Champomier-Vergès, M.C., Cornet, M., Crutz-Le, C., Dudez, A. M., Martin, V., Beaufils, S., Darbon-Rongère, E., Bossy, R., Loux, V. y Zagorec, M., 2005. The complete genome sequence of the meat-borne lactic acid bacterium Lactobacillus sakei 23K. En: Nature Biotechnology, 23(12), pp.1527-1533.

DeGeer S. L., Wang, L., Hill, G. N., Singh, M., Bilgili, S. F. y Bratcher, C. L., 2016. Optimizing application parameters for lactic acid and sodium metasilicate against pathogens on fresh beef, pork and deli meats. En: Meat Science, 118, pp.28-33.

Dormedy, E. S., Brashears, M. M., Cutter, C. N. y Burson, D. E., 2000. Validation of acid washes as critical control points in hazard analysis and critical control point systems. En: Journal of Food Protection, 63, pp.1676-1680.

EFSA-ECDC, 2016. The European Union summary report on trends and sources of zoonoses, zoonotic agents and food-borne outbreaks in 2015. En: EFSA Journal, 14(12), pp.4634.

European Commission, [s.d.]. RASFF Portal. Food and feed safety alerts [En línea].[s.l.]: EuropeanCommission. [Consulta: 7 demarzo de 2018]. Disponible en: https://webgate.ec.europa.eu/rasff-window/ portal/?event $=$ searchResultList

Ferreira,V., Wiedmann, M., Teixeira, P.y Stasiewicz, M. J., 2014. Listeria monocytogenes persistence in food-associated environments: epidemiology, strain characteristics, and implications for public health. En: Journal of Food Protection, 77(1), pp.150-170.

García, L., Brugnini, G., Rodriguez, S., Mir, A., Briano, B., Carriquiry, J. y Rufo, C., 2015. Vida útil de carne fresca de res envasada al vacío a $0^{\circ} \mathrm{C} y+4^{\circ} \mathrm{C}$. En: Producción Agropecuaria y Desarrollo Sostenible, 4, pp.27-45.

Gill, C. O. y Badoni, M., 2004. Effects of peroxyacetic acid, acidified sodium chlorite or lactic acid solutions on the microflora of chilled beef carcasses. En: International Journal of Food Microbiology, 91, pp.43-50.

Guerrieri, E., de Niederhäusern, S., Messi, P., Sabia, C., Iseppi, R., Anacarso, I. y Bondi, M., 2009. Use of lactic acid bacteria (LAB) biofilms for the control of Listeria monocytogenes in a small-scale model. En: Food Control, 20, pp.861-865.

Holzapfel W., Geisen R. y Schillinger U., 1995.Biological preservation of foods with reference to protective cultures, bacteriocins and food grade enzymes. En: International Journal of Food Microbiology,24(3), pp.343-362.

Jones, R. J., 2004. Observations on the succession dynamics of lactic acid bacteria populations in chill-stored vacuum-packaged beef. En: International Journal of Food Microbiology, 90(3), pp.273-282.

Koohmaraie, M., Arthur, T. M., Bosilevac, J. M., Guerini, M., Shackelford, S. D. y Wheeler, T. L., 2005. Post-harvest interventions to reduce/eliminatepathogens in beef. En: Meat Science, 71, pp.79-91.
McLauchlin, J. M., Mitchell, R. T., Smerdonc, W. J. y Jewell, K., 2004. Listeria monocytogenes and listeriosis: a review of hazard characterisation for use in microbiological risk assessment of foods. En: International Journal of Food Microbiology, 92(1), pp.15-33.

Metselaar, K. I., den Besten, H. M. W., Abee, T. A., Moezelaar, R. y Zwietering, M. 1. H., 2013.Isolation and quantification of highly acid resistant variants of Listeria monocytogenes. En: International Journal of Food Microbiology, 166(3), pp.508-514.

Mor-Mur, M. y Yuste, J., 2010. Emerging bacterial pathogens in meat and poultry: an overview. En: Food and BioprocessTechnology, 3, pp.24-35.

MSP, 2017. Boletín epidemiológico - Mayo 2017 [En línea]. Montevideo: MSP. [Consulta: 7 de marzo de 2018]Disponible en http://www.msp gub.uy/publicaci\%C3\%B3n/bolet\%C3\%ADnepidemiol\%C3\%B3gico-mayo-2017

Nychas, G., Panos, Skanadamis, P., Tassou, C. y Koutsoumanis, K., 2008. Meat spoilage during distribution. En: Meat Science, 78, pp.77-89.

Oh, D. H. y Marshall, D. L., 1993. Antimicrobial activity of ethanol, glycerol monolaurate or lactic acid against Listeria monocytogenes. En: International Journal of Food Microbiology, 20(4), pp.239-246.

Rajkovic, A., Smigic, N. y Devlieghere, F., 2010. Contemporary strategies in combating microbial contamination in food chain. En: International Journal of Food Microbiology, 141, pp.29-42.

Skandamis, P. N., Yoon, Y., Stopforth, J. D., Kendall, P. A. y Sofos, J. N., 2008. Heat and acid tolerance of Listeria monocytogenes after exposure to single and multiple sublethal stresses. En: Food Microbiology, 25(2), pp.294-303.

Sorrels, K. M., Enigl, D.C. y Hatfield, J. R., 1989. Effect of $\mathrm{pH}$, acidulant, time, and temperature on the growth and survival of Listeria monocytogenes. En: Journal of Food Protection, 52, pp.571-573.

Theron, M. M. y Lues, J. F. R., 2007. Organic acids and meat preservation: a review. En: Food Reviews International, 23(2), pp.141-158.

Unión Europea. Reglamento (UE) No 101/2013. Diario Oficial de la Unión Europea, 05 de febrero de 2013, L 34/1.

Vignolo, G., Saavedra, L., Sesma, F. y Raya, R., 2012. Food bioprotection: lactic acid bacteria as natural preservatives. En: Bhat, Rajeev, Alias, Abd Karim y Paliyath, Gopinadhan, eds. Progress in food preservation. Cap.22. Nueva Jersey: John Wiley \& Sons. pp.453-483.

Woolthuis, C. H. J. y Smulders, F. J. M., 1985. Microbial decontamination of calf carcasses by lactic acid sprays. En: Journal of Food Protection, 48(10), pp.832-837.

Yoder, S. F., Henning, W. R., Mills, E. W., Doores, S., Ostiguy, N. y Cutter, C. N., 2012. Investigation of chemical rinses suitable for very small meat plants to reduce pathogens on beef surfaces. En: Journal of Food Protection, 75(1), pp.14-21.

Youssef, M. K., Yang, X., Badoni, M. y Gill, C. O., 2012. Effects of spray volume, type of surface tissue and inoculum level on the survival of Escherichia coli on beef sprayed with 5\% lactic acid. En: Food Control, 25(2), pp.717-722. 